\title{
La revolución y el problema del origen. La fundación reconsiderada desde un horizonte político posfundacional $^{*}$
}

\author{
The revolution and the problem of the beginning. The foundation \\ reconsidered since a postfoundational perspective
}

\author{
Anabella Di Pego \\ anadipego@gmail.com \\ (Universidad Nacional de La Plata-CONICET, Buenos Aires, Argentina)
}

\begin{abstract}
Resumen: En este trabajo nos adentramos en la problemática de la revolución, deteniéndonos especialmente en la cuestión de la fundamentación del nuevo comienzo que esta trae consigno. Nos detendremos en la crítica de Arendt del recurso al absoluto en la tradición del pensamiento político para sustentar la tarea de fundación. Sin embargo, procuramos mostrar que Arendt no se contenta con señalar la ausencia de fundamentos absolutos sino que afronta la tarea de repensar un fundamento contingente y provisorio pero de relativa estabilidad. En este sentido, entendemos que la tematización de la fundación en Arendt da lugar a lo que puede denominarse una concepción posfundacional de lo político.
\end{abstract}

Palabras clave: revolución; fundación; fundamento de lo político; contingencia; autoridad.

\begin{abstract}
In this work we deal with the problematic of the revolution, pondering especially the question of the foundation of a new beginning. We analyze Arendt's criticism of the tradition of political thought with regard to the role of the absolute in the foundation. At the same time, we try to show that Arendt's view is not limited to point out the absence of absolute foundations, but it faces the task of rethinking a contingent and temporary foundation with a relative stability. In this way, Arendt's approach to foundation, as we understand it, belongs to what has been called recently a postfoundational perspective of the political.
\end{abstract}

Keywords: revolution; foundation; fundament of the political, contingency; authority.

DOI: http://dx.doi.org/10.11606/issn.2318-9800.v21i3p79-92

\section{Introducción}

El libro Sobre la revolución (1963) de Hannah Arendt vuelve a situar en el centro de la reflexión política el problema de la fundación, que había constituido uno de los ejes fundamentales de la teoría y de la filosofía política moderna. Si

\footnotetext{
* Quisiera agradecer especialmente a los organizadores y participantes de las IV Jornadas Internacionais Hannah Arendt - Sobre a Revolução - 50 anos realizadas del 21 al 24 de octubre de 2013 en la Unicamp. Fue a partir de los intercambios y de las discusiones allí suscitadas que este artículo ha tomado forma.
} 
bien la relevancia de la fundación no ha pasado inadvertida para los intérpretes ${ }^{1}$, ha suscitado mayor atención la irrupción y la novedad que caracterizan a la revolución como "manifestación de la capacidad casi milagrosa de los seres humanos de iniciar, de innovar, de hacer saltar por los aires el continuo histórico" (Birulés, 2007, p.115). En este sentido, Marchart sostiene que el análisis de Arendt sobre la revolución constituye la "concretización histórica” (Marchart, 2011, p.84) de su teoría de la acción desarrollada en La condición humana. Cuando la problemática de la fundación ha sido objeto de análisis se ha vinculado a la reivindicación arendtiana del sistema de consejos $^{2}$ o a la creación de espacios públicos y su establecimiento institucional ${ }^{3}$. Por nuestra parte, nos interesa abordar el problema teórico que la fundación suscita respecto de su propia fundamentación.

Resulta notoria y manifiesta la tentativa arendtiana de sustraer el problema del fundamento de los absolutos a los que había recurrido la tradición moderna soberanía, voluntad general, derecho natural, verdades autoevidentes, entre otras. Esto implica el rechazo de un fundamento absoluto, pero no significa que los nuevos comienzos carezcan completamente de fundamentos ${ }^{4}$. Más bien, consideramos que se trata de retomar el problema de la fundamentación de lo político desmontando la dicotomía tradicional entre fundamento absoluto o ausencia total de fundamento. De este modo, entendemos que en el abordaje arendtiano de la fundación de un nuevo cuerpo político - y de su fundamentación - se está jugando una concepción novedosa y no fundacional ${ }^{5}$ o posfundacional (cf. Marchart, 2009), en donde lo político se inscribe en una dinámica contingente, pero al mismo tiempo, se encuentra sustentado en marcos de relativa estabilidad que no resultan meramente arbitrarios.

Antes de adentrarnos en el problema que toda revolución trae consigo respecto de la fundación de un nuevo cuerpo político y su fundamento - en términos arendtianos la cuestión del "principio del origen" -, quisiéramos realizar algunas aclaraciones y consideraciones generales sobre el libro de Arendt. Sin lugar a dudas, Sobre la revolución constituye una obra polémica que no ha dejado de suscitar controversias a lo largo de los años transcurridos desde su publicación. En el momento de su aparición fue recibida con críticas denostadoras por parte de los historiadores ${ }^{6}$ y tampoco fue

1 Véanse especialmente: Enegrén, 1994, pp.53-87; Wellmer, 2006, pp.220-241; y Canovan, 2000, p.61. Este último trabajo destaca el papel de los límites y de las instituciones como marcos posibilitadores de la política en Arendt.

2 Al respecto remitimos a: Muldoon, 2011, pp.396-417; Disch, 2011, p.352; y Marchart, 2011, p.89.

3 Véanse especialmente: King, 2011, p.38; y Wellmer, 2008, p.107.

4 Nos distanciamos en este punto de la lectura de Dana Villa que destaca la ausencia de fundamentos [groundless] en la perspectiva arendtiana. Véase: Villa, 1996, p.157.

5 En este sentido, Honig señala: "considero que su análisis de la experiencia americana forma parte de una re-teorización de la autoridad para una política no-fundacional" (Honig, 1991, p.98).

6 Recordemos algunas de las palabras de la reseña que oportunamente escribió el historiador inglés: "La primera dificultad que encuentran los estudiantes de historia o de sociología de las revoluciones en la señora Arendt es un cierto carácter metafísico y normativo de su pensamiento, que va bien 
bien acogida en ese entonces en el ámbito de la teoría política, especialmente el francés, por su análisis crítico de la Revolución francesa y de la cuestión social ${ }^{7}$, y por su reposicionamiento de la Revolución americana, cuya caracterización como una revolución resulta asimismo cuestionable ${ }^{8}$. A pesar de todo esto, el libro de Arendt lejos de haber pasado al olvido, sigue interpelándonos para pensar el potencial de lo político en el derrotero de la modernidad, que ha fulgurado en los momentos revolucionarios pero no ha podido desplegarse en todas sus implicancias. De modo que las revoluciones modernas no son sólo manifestación e irrupción de lo político, sino que también detentan un potencial no realizado plenamente que nos remite al problema de la fundación.

Asimismo, es preciso destacar que no es un interés histórico en torno de las revoluciones lo que sustenta el estudio arendtiano (cf. Forti, 1996, p.286), sino fundamentalmente sus implicancias y su significado político para nuestros días. Con las siguientes palabras, lo explicita la propia Arendt en el primer capítulo de su libro:

No nos interesa la historia de las revoluciones en sí misma (su pasado, sus orígenes y el curso de su desarrollo). Si queremos saber qué es una revolución - sus implicaciones generales para el hombre en cuanto ser político, su significado político para el mundo en el que vivimos, su papel en la historia moderna - debemos dirigir nuestra atención a aquellos momentos de la historia en que hicieron su aparición las revoluciones, en que adquirieron una especie de forma definida y comenzaron a cautivar el espíritu de los hombres, con independencia de los abusos, crueldades y atentados a la libertad que puedan haberles conducido a la rebelión (Arendt, 1992, p.45).

En las páginas siguientes nos adentramos en la problemática de la revolución, siguiendo como hipótesis de lectura, que la tematización de la fundación en Arendt da lugar a lo que puede denominarse una política posfundacional, que se sustenta en fundamentos contingentes pero a la vez de relativa estabilidad. A partir de esto, indagamos en torno del acto constituyente, su fundamentación y el tipo de fundación en que está pensando Arendt, con sus implicancias para una crítica no sólo de las revoluciones sino también de los precarios e insuficientes sustentos políticos de nuestros sistemas democráticos.

con un, a veces bastante explícito, idealismo filosófico pasado de moda" (Hobsbawm, 1965, p.253).

7 En nuestro recorte del tema y debido a la extensión limitada del trabajo, no nos resulta posible abordar el polémico tratamiento arendtiano del papel de la cuestión social en la Revolución francesa. Remitimos al respecto a nuestros artículos: Di Pego, 2006, pp.101-123; y Di Pego, 2005, pp.39-69.

8 Posteriormente, con la caída del muro de Berlín en 1989, el libro gozó de un nuevo auge a la luz de los movimientos y luchas por la liberación de los países que se encontraban bajo el dominio de la Unión Soviética. 


\section{La revolución y el problema del origen}

Para comenzar nuestro desarrollo argumentativo, resulta necesario precisar con antelación el modo en que Arendt entiende el concepto de revolución en su libro. En una primera aproximación, la noción de revolución nos remite a un cambio político llevado a cabo mediante la violencia, sin embargo, esto no alcanza para caracterizarla puesto que en la Antigüedad también encontramos cambios políticos violentos pero la revolución es un fenómeno político específicamente moderno. La revolución, además de la violencia y de un cambio político, implica "el nacimiento de una realidad enteramente nueva" (Arendt, 1992, p.22) que interrumpe el curso de la historia. Este pathos de la novedad es la marca característica de la revolución, que no se encontraba presente en la Antigüedad, en donde toda fundación era en realidad una restauración de una realidad pasada. La concepción rectilínea de la historia que el cristianismo trajo consigo se encuentra a la base de la posibilidad de pensar la revolución como un nuevo comienzo de la historia. Pero este nuevo comienzo de la historia no es meramente un estallido o una irrupción de la novedad, sino que Arendt está pensando en la formación de un cuerpo político nuevo o en el establecimiento de una forma completamente nueva de gobierno. De ahí que la revolución se encuentre íntimamente vinculada con la fundación y que Arendt considere que, a pesar de no haberse dedicado específicamente a la revolución, Maquiavelo fue un precursor y una "figura (...) relevante para una historia de la revolución”, puesto que fue "el primero que meditó sobre la posibilidad de fundar un cuerpo político permanente, duradero y perdurable" (idem, p.37).

Pero una vez delineados los vínculos entre revolución y fundación, aparece también lo que Arendt denomina "la perplejidad (...) inherente a la tarea de la fundación" (Arendt, 1992, p.40), y que nos remite al problema del origen o de la fundamentación del nuevo comienzo, es decir, del origen de la autoridad de las nuevas leyes y del nuevo sistema de gobierno. La cuestión es ¿por qué habría que obedecer las leyes y el gobierno establecido por algunos hombres? La respuesta tradicional fue recurrir al "molde del antiguo absoluto que derivaba de una autoridad establecida por Dios, reemplazando de este modo un orden terrenal cuya sanción había estado constituida, por los dictados de un Dios omnipotente y cuya última fuente de legitimidad había sido la noción de una encarnación de Dios en la tierra" (idem, ibidem). Este recurso al absoluto para "resolver" el problema del origen constituye un lugar común en la historia del pensamiento político, y por eso, incluso Maquiavelo que había procurado delimitar los asuntos políticos de cualquier tratamiento religioso, imploraba no obstante por la ayuda y la inspiración divina para los legisladores que debían acometer la fundación de una nueva comunidad política. El problema de la fundamentación del origen recorre todo el libro hasta el final, pero ya en el primer capítulo, Arendt adelanta su propio posicionamiento al respecto: 
Veremos después cómo esta última etapa de la tarea revolucionaria, el hallazgo de un nuevo absoluto que reemplace al absoluto del poder divino, carece de solución, debido a que el poder, dado el supuesto de la pluralidad humana, nunca puede aspirar a la omnipotencia, ya que las leyes que dependen del poder humano nunca pueden ser absolutas. Así, esta «llamada a los cielos» de Maquiavelo, como la hubiera calificado Locke, no fue inspirada por ningún sentimiento religioso, sino que fue dictada exclusivamente por el deseo de «escapar de esta dificultad» (Arendt, 1992, p.40).

En la cita precedente, podemos observar que en la medida en que los asuntos humanos suponen la pluralidad no es posible fundarlos sobre ningún absoluto, sin embargo, de esto no se sigue que Arendt sea escéptica respecto de la fundamentación de lo político ni que sentencie que carece por completo de fundamentos. Antes bien, Arendt está realizando un desmontaje del movimiento dicotómico tradicional por el cual los fundamentos son absolutos e inconmovibles o no constituyen fundamentos en sentido estricto. De esta manera, el problema de la fundamentación oscilaría entre los dos polos antagónicos de los fundamentos absolutos y de la ausencia total de fundamentos. Lo que Arendt está proponiendo es un desplazamiento o un replanteamiento del problema, a partir de lo cual se asume el desafía de pensar una fundación sin absolutos, cuya fundamentación implica la aceptación de la contingencia irreductible de los asuntos humanos. Lo político en tanto modalidad de manifestación de los asuntos humanos no puede ser clausurado en torno de un absoluto, puesto que la pluralidad y su dinámica contingente, abierta y mutable siempre exceden y sobrepasan la limitación de cualquier absoluto. En este sentido, el abordaje de Arendt de la fundación/fundamentación de lo político ${ }^{9}$ en Sobre la revolución sitúa la problemática en un nuevo horizonte que con posterioridad, en la segunda mitad del siglo $X X$, se ha vuelto el lugar común de la filosofía política, especialmente la francesa, y que Oliver Marchart ha denominado como "posfundacionalismo":

El posfundacionalismo (...) no debe confundirse con el antifundacionalismo o con un vulgar posmodernismo del «todo vale», hoy demodé, dado que un enfoque posfundacional no intenta borrar por completo esas figuras del fundamento, sino debilitar su estatus ontológico. El debilitamiento ontológico del fundamento no conduce al supuesto de la ausencia total de todos los fundamentos, pero sí a suponer la imposibilidad de un fundamento último, lo cual es algo enteramente distinto, pues implica la creciente conciencia, por un lado, de la contingencia y, por el otro, de lo político como el momento de un fundar parcial y, en definitiva, siempre fallido (Marchart, 2009, pp.14-5).

La forma en que Arendt tematiza esta dimensión fallida, parcial y contingente de la fundación es a través de la idea de que la tarea de la revolución no es solamente la fundación de un cuerpo político estable sino también la "fundación de la libertad",

\footnotetext{
9 Aunque Arendt no distingue entre la política (the politics, die Politik, la politique) y lo político (the political, das Politische, le politique), su propia concepción constituye una tematización de lo político en su especificidad. Véase al respecto: Lefort, 2000, pp.131-144.
} 
es decir, que ese cuerpo político "garantice la existencia de un espacio donde pueda manifestarse la libertad” (Arendt, 1992, p.124). De esta manera, aunque Arendt señala que la revolución y la fundación "son fenómenos casi correlativos" (idem, p.125), sin embargo, no toda fundación asegura la preservación del espíritu revolucionario, y ahí se cifra el éxito o el fracaso de una revolución. En este sentido, Arendt advierte sobre el relativo éxito de la revolución americana, “donde tuvo plena realización la fundación de un nuevo cuerpo político y donde, por consiguiente, en algún sentido, la Revolución alcanzó su objetivo real” (idem, p.126), pero en donde sin embargo, se fracasó en "el afianzamiento del espíritu que inspiró el acto de fundación” (idem, ibidem), es decir, no se pudo asegurar el establecimiento de espacios en donde se preservara la libertad y la participación pública que había dado origen a la propia revolución ${ }^{10}$.

La peculiaridad de la concepción arendtiana de la revolución reside, entonces, en que ésta no es mera interrupción de la historia por la irrupción de la novedad, ni tampoco solamente la fundación de un cuerpo político estable, sino que la revolución y su momento fundamentalmente político, se dirime en la tensión irresoluble entre esos dos movimientos hacia la novedad y hacia la fundación, y cuando alguno de ellos resulta anulado por el otro, o sobredimensionado unilateralmente, la revolución fracasa y la política se eclipsa. Así, Arendt nos advierte que una revuelta violenta, por más novedosa y liberadora que sea, no puede dar lugar a una revolución si no hay hombres preparados para tomar el poder y fundar un cuerpo político (Arendt, 1992, p.116), pero por otra parte, la fundación por sí sola tampoco detenta un carácter revolucionario, a menos que traiga consigo un perfeccionamiento de la nueva forma de gobierno (cf. idem, p.143), de manera que garantice la preservación del espíritu del acto de fundación (cf. idem, p.126), es decir, de la libertad y la participación que la inspiraron.

La revolución se define entonces por la tensión que la atraviesa entre la emergencia de un nuevo comienzo con su impronta de novedad y la fundación de un cuerpo político con su preocupación por la estabilidad y la duración. Pero esta tensión no debe concebirse como una oposición irreconciliable entre elementos contrapuestos, sino como elementos en cuya dinámica de interacción en conflicto se constituye lo político. Lo que ha sucedido es que una vez acaecidas las revoluciones estos elementos han cristalizado en posiciones excluyentes que han terminado por socavar la articulación de novedad y de perdurabilidad que implica lo político. $Y$ en esta escisión de la que surgieron después de las revoluciones, el liberalismo progresista y el conservadurismo encarnando dos vertientes opuestas, Arendt cree

10 De manera que no puede sostenerse como pretende Habermas en su mordaz comentario del libro de Arendt que la Revolución americana sea plenamente exitosa frente al fracaso absoluto de la francesa. Véase: Habermas, 2000, pp.200-5. 
encontrar un "síntoma de nuestra perdición” (Arendt, 1992, p.231), en tanto supone un vaciamiento de la conflictividad y la tensión constitutiva de lo político. Esta escisión entre novedad y estabilidad también se encuentra a la base de nuestro vocabulario político moderno, "que se presenta siempre en pares de conceptos opuestos: derecha e izquierda, reaccionario y progresista, conservadurismo y liberalismo" (idem, ibídem). Frente a esto, Arendt explicita su ímpetu por volver a los conceptos políticos y revolucionarios, para desmantelar las oposiciones y pensarlos nuevamente en su entramado conflictivo constitutivo:

Desde el punto de vista filológico, el esfuerzo que se realiza para reconquistar el espíritu perdido de la revolución, debe consistir, en buena parte, en repensar y combinar de modo significativo todo lo que nuestro vocabulario político nos ofrece en términos de oposición y contradicción (Arendt, 1992, p.231).

De modo que Arendt está concibiendo que lo político mismo, y no sólo la revolución, se dirime en ese juego de oposición y conflicto entre la novedad y la perdurabilidad. Lo político no es sólo irrupción de la novedad, manifestación de la singularidad y nuevo origen, sino que esto mismo requiere un marco de estabilidad que asegure y haga posible la emergencia de la novedad. Por eso es que Arendt vuelve a las revoluciones y analiza específicamente qué fue lo que ellas pudieron fundar y establecer de manera perdurable. Con lo cual, el tópico de la fundación resulta central, pero no sería cualquier tipo de fundación y de ahí que Arendt finalmente consigne, como hemos visto, el fracaso de ambas revoluciones, puesto que de alguna manera trataron de suturar el problema del origen y con ello clausuraron la fuente misma de lo político. Detengámonos un momento, entonces, en la cuestión del origen que, como ha advertido Claudia Hilb (2012), constituye uno de los problemas centrales de toda fundación. Las revoluciones, advierte Arendt, “constituyen los únicos acontecimientos políticos que nos ponen directa e inevitablemente en contacto con el problema del origen" (Arendt, 1992, p.21).

Toda fundación nos enfrenta al problema de los fundamentos de ese nuevo origen y los revolucionarios lo abordaron en los términos tradicionales de la búsqueda de un absoluto trascendente que lo sustrajera de la contingencia y de la arbitrariedad. Esto pone de manifiesto que el proceso de secularización no ha deslindado simplemente la política de la religión, sino que más bien ha llevado consigo e introducido la necesidad del absoluto en el seno mismo de la política. En este sentido, la búsqueda de las revoluciones

por hallar un principio absoluto de donde derivar autoridad para su Derecho y poder, podría ser perfectamente interpretado como una prueba de que el Estado y la política necesitaban la sanción religiosa con mayor urgencia que la religión y las Iglesias habían necesitado nunca el apoyo de los príncipes (Arendt, 1992, p.164). 
Por eso, Arendt no duda en señalar que el "problema más espinoso de todo gobierno revolucionario" lo constituye "el problema de un absoluto" (idem, p.161). Los revolucionarios franceses sustentaron la fuente del poder y del derecho en el pueblo, o en otras palabras, en la voluntad general, y para ello transformaron al pueblo en el absoluto que permitía clausurar la circularidad de toda fundación. Los revolucionarios norteamericanos distinguieron entre el origen del poder que brota del pueblo y el origen o la fuente de legitimidad del derecho, pero de todas formas buscaron éste último también en un absoluto, "cuyo puesto está «arriba», en alguna región más elevada y trascendente" (idem, p.189).

La revolución, tanto para quienes se embarcaban en esta empresa política como para quienes reflexionaban sobre ella, se presenta como una tarea paradójica puesto que en tanto que interrumpe la temporalidad parece requerir de una fuente o de un origen que haga posible esa suspensión y que a la vez explique la emergencia de la novedad. Arendt nos advierte que esto se debe a "los antiguos hábitos de pensamiento de Occidente, según los cuales todo origen completamente nuevo requiere de un absoluto del que brotar y a través del cual poder ser «explicado»" (Arendt, 1992, p.213). De lo que se trata en la perspectiva arendtiana sería de mostrar que el problema del origen supone una cierta arbitrariedad, es decir un carácter contingente que no puede ser reducido a un absoluto y que resulta consecuentemente constitutivo de los asuntos humanos. El único entre los pensadores revolucionarios que logró sustraerse a este impulso de sustentar lo político en algún principio absoluto trascendente fue Montesquieu (cf. idem, p.195). La razón fundamental es que entendía la ley, siguiendo la concepción romana, como una regulación de las relaciones entre las personas que no requería de una validez absoluta porque no era concebida como un mandamiento incondicional. Pero la concepción moderna de la ley a pesar de sus aparentes reminiscencias romanas hunde sus raíces en el modelo judeo-cristiano de los mandamientos, entendidos como la palabra divina que establece las obligaciones según las cuales los hombres deben comportarse. En la época moderna este modelo se mantuvo sólo que "el Derecho natural ocupó el lugar de la divinidad", y en este marco exclusivamente, es dónde se puede plantear el problema de la legitimidad de la ley como remitiendo necesariamente a un absoluto. Al respecto, Arendt sostiene:

Sólo en la medida en que entendamos por ley un mandamiento al que los hombres deben obediencia sin consideración a sus acuerdos mutuos y consentidos [consent and mutual agreements], la ley requerirá una fuente trascendente de autoridad [transcendent source of authority] para su validez, esto es, un origen que esté más allá del poder del hombre [beyond human power] (idem, p.196) ${ }^{11}$.

11 Traducción corregida. Hemos reemplazado "su consentimiento, y los acuerdos mutuos" por "sus acuerdos mutuos y consentidos”. Véase el original en inglés: Arendt, 1990, p.189. 
Arendt procede a desarmar este modelo de ley mandamiento sustentado en un absoluto que procura neutralizar la arbitrariedad de lo político, y en su lugar lo que emerge es una concepción de la legitimidad de la ley que se funda en el marco de relativa estabilidad que ofrecen los acuerdos mutuos y que no se presenta como un absoluto pero tampoco como mera arbitrariedad, sino que opera como un fundamento que otorga un sustento perdurable, que, no obstante, no se sustrae de la contingencia de los asuntos humanos. De esta manera, Arendt procede a resolver o más bien disolver el problema del absoluto en política para volver a plantear la cuestión de su origen remitiendo a un fundamento contingente aunque no meramente arbitrario que sitúa lo político en un horizonte posfundacional.

(...) existe una solución para las perplejidades del origen [perplexities of beginning] que no requiere ningún absoluto para romper el círculo vicioso en el que todas las cosas originarias parecen quedar atrapadas. Lo que salva al acto del origen [act of beginning] de su propia arbitrariedad es que conlleva consigo su propio principio [principle], o, para ser más precisos, que origen y principio, principium y principio, no sólo son términos relacionados sino que son coetáneos. El absoluto del que va a derivar su validez el origen [beginning] y que debe salvarlo, por así decirlo, de su inherente arbitrariedad es el principio [principle] que, junto a él, hace su aparición en el mundo. La forma [the way] en que el iniciador comienza cuanto intenta hacer, dicta la ley de acción [the law of action] que regirá los actos de todos aquellos que se le unen para participar en la empresa y llevarla a término. En cuanto tal, el principio inspira los hechos que van a seguirlo y continúa siendo visible durante todo el tiempo que perdura la acción (Arendt, 1992, p.220)12.

De la cita precedente, quisiéramos detenernos brevemente en tres cuestiones. En primer lugar, observamos que Arendt distingue entre origen o comienzo [beginning] y principio [principle], siendo éste último el que permite fundamentar el origen y salvarlo "de su inherente arbitrariedad". De manera que todo origen tiene un principio en el que se sustenta, pero este principio no es algo completamente diferente del origen sino que sólo con él puede hacer su aparición.

La cuestión es, entonces, en segundo lugar, de qué se trata este principio del origen o del comienzo. Lo que se manifiesta en todo comienzo es la propia capacidad humana de iniciar algo, de comenzar algo nuevo, o en otras palabras, la natalidad, es decir, el hecho de que el hombre es el principio de todo comienzo, y por lo tanto de la libertad misma ${ }^{13}$. Por eso Arendt, advierte que "es inútil [futile] la búsqueda de un absoluto con que romper el círculo vicioso en el que queda atrapado inevitablemente todo origen [beginning], debido a que este «absoluto» reside en el propio acto de dar origen a algo [act of beginning itself]" (Arendt, 1992, p.210). El problema del

12 Traducción corregida. Véase el original en inglés: Arendt, 1990, p.212.

13 “Nos interesa (...) la idea (...) según la cual los hombres están preparados para la tarea paradójica de producir un nuevo origen porque ellos mismos son orígenes nuevos y, de ahí, iniciadores (...) la auténtica capacidad para el origen está contendida en la natividad, en el hecho de que los seres humanos aparecen en el mundo en virtud del nacimiento" (Arendt, 1992, pp.218-9). 
origen atraviesa desde sus inicios el pensamiento político, sólo que antes de la época moderna, se encontraba vedado por las leyendas fundacionales que procuraban dar cuenta de "un acontecimiento nuevo e inconexo que venía a romper la secuencia del tiempo histórico" (idem, p.211). Pero con las revoluciones, el acto de fundación que hasta ese entonces había sido objeto de leyendas que se remontaban a tiempos inmemorables, se llevó a cabo a plena luz del día y podía ser evocado y recordado por quienes habían participado en la empresa revolucionaria. Lo que entonces se hizo manifiesto es que el manantial de la autoridad de un cuerpo político nuevo "iba a ser más el propio acto de fundación [act of fundation itself] que un Legislador inmortal o una verdad evidente por sí misma o cualquier otra fuente trascendente y transmundana” (idem, p.210).

En tercer lugar, el principio del origen no remite solamente a esta capacidad humana de iniciar algo nuevo sino también a "la forma [the way] en que el iniciador comienza cuanto intenta hacer", de manera tal que esa forma se pueda volver ley o regla para los actos sucesivos que emprendan quienes participan y continúen con la iniciativa. Esto a su vez, nos otorga la clave para distinguir la potencialidad política de un comienzo de una mera interrupción de la temporalidad, que puede estar dada por una guerra, un golpe de estado, un levantamiento, u otras formas meramente violentas. Esto supone que no todo nuevo comienzo ni cualquier acción o emprendimiento colectivo es inherentemente un momento político. La especificidad de lo político no reside solamente en la novedad y la acción conjunta, sino fundamentalmente en el "modo" o la "forma” en que esa acción se lleva a cabo introduciendo algo nuevo. De manera que no cualquier principio salva la arbitrariedad del comienzo sino sólo aquel que establece un modo que puede ser aplicado como regla posterior. Este modo sería, a nuestro entender, una forma de interacción que no puede anular la pluralidad, en tanto condición que la hizo posible. En la medida en que este modo que opera como regla de la acción ulterior "salva al acto del origen [beginning] de su propia arbitrariedad" (Arendt, 1992, p.220), constituye el fundamento de ese nuevo origen. Un fundamento contingente pero relativamente estable en la medida en que delimita las formas de interacción aceptadas como norma de acción ${ }^{14}$.

La acción entonces para ser estrictamente política, además de la novedad y la pluralidad, requeriría de un "modo" y de un marco que asegure el mantenimiento de las condiciones de su propia posibilidad. Es decir, una acción puede ser concertada

14 En este sentido no se trataría de una sustitución de la cuestión del fundamento por la transparencia del origen, como sostiene Enegrén: "Arendt sustituye la obsesión de un fundamento que estaría más acá de todas las cronologías por la idea de una transparencia del punto de partida como comienzo radical de una historia libre de modelarse según un esquema inédito" (Enegrén, 1994, p.83). Más bien, nuestro análisis muestra que Arendt sigue empeñada en dar una respuesta al problema de la fundación aunque de una manera no convencional que implica concebir un fundamento concertado, provisorio y contingente pero capaz de dotar de autoridad y de relativa estabilidad al nuevo origen. 
e introducir novedad pero si sus consecuencias socavan o suspenden la pluralidad entonces no puede ser considerada estrictamente "política”. En este sentido, aunque un régimen dictatorial tenga su origen en una acción concertada su "principio" no puede ser considerado político en sentido estricto porque no sólo no contempla la preservación de la pluralidad sino que socava deliberadamente las condiciones que la hicieron posible, es decir, su principio no puede obrar como regla de acción posterior ${ }^{15}$. Y acá nuevamente se plantea que lo político requiere de marcos de estabilidad que delimiten "modos" capaces de preservar la pluralidad, con lo que volvemos al problema de la fundación, pero no de cualquier tipo de fundación sino de una fundación que garantice la posibilidad de que la acción plural se torne regla de acción del acontecer posterior.

El problema de la fundación remite precisamente al modo y la forma que la organización política establece para la interacción presente y futura, de ahí que actúe al mismo tiempo como principio y regla de la acción política posterior. En el análisis de la revolución americana, Arendt encuentra elementos que le permiten delinear y profundizar en qué consistiría el principio del origen entendido como modo de interacción:

El curso de la revolución americana tiene una historia inolvidable y nos enseña una lección única en su género; en efecto, esta revolución no fue resultado de un estallido, sino que fue preparada por hombres en deliberación compartida [common deliberation] y con la fortaleza que se derivaba de las promesas mutuas [mutual pledges]. El principio que se abrió paso durante los fatídicos años en que se establecieron las fundaciones -no por la fuerza de un arquitecto sino gracias al poder combinado de muchos-, fue el principio combinado de la promesa mutua y de la deliberación en común [mutual promise and common deliberation]; el propio acontecimiento fue el que decidió, como Hamilton había dicho repetidamente, que los hombres «son realmente capaces... de establecer buenos gobiernos a partir de la reflexión y la elección», que no «están eternamente condenados a que sus constituciones políticas dependan del accidente y de la fuerza» (Arendt, 1992, p.221) ${ }^{16}$.

El legado de la revolución americana parece residir en que en ella, el principio del nuevo cuerpo político fue la acción concertada entre las personas - con su novedad inherente - y el marco de perdurabilidad de las promesas mutuas ${ }^{17}$. Lo que esa revolución mostró es que el acto de la fundación política puede sustentarse en la

15 En el caso del bullying o del hostigamiento escolar, por ejemplo, aunque se trata de una acción colectiva y concertada, atenta contra la pluralidad puesto que excluye al otro implicado de esa misma acción que lo afecta directamente, por lo que no detentaría en absoluto de carácter político sino que por el contrario sería antipolítico, en el sentido de que socava las bases que hacen posible lo político.

16 Traducción corregida. Véase el original en inglés: Arendt, 1990, pp.213-214.

17 No nos detendremos aquí en las particularidades de la promesa mutua en Arendt, pero quisiéramos advertir que no debe ser pensada en términos meramente contractualistas. Al respecto remitimos especialmente a Smola, 2012. 
deliberación ${ }^{18}$ compartida y en las promesas mutuas, y que el poder político que allí surge, excede o resulta imposible de reducirse a la mera fuerza o violencia. Pero si bien la revolución americana fundó un cuerpo político basándose en esos principios, no logró que esos principios se tornaran regla de las acciones subsiguientes, es decir, fracasó al no poder hacer de la acción concertada y las promesas mutuas, la dinámica de funcionamiento permanente de ese cuerpo político, puesto que quedaron reservadas casi exclusivamente al momento fundacional. Arendt considera que este fracaso se produjo cuando los padres fundadores no lograron que las asambleas municipales, que habían sido los verdaderos órganos de deliberación de donde brotaba el poder, fuesen contempladas en la constitución como una instancia de participación a ser preservada. Así la revolución americana disolvió luego de la fundación las bases del poder que la habían originado.

\section{Consideraciones finales}

El análisis arendtiano de la revolución y de la fundación, tal como se ha mostrado a lo largo del trabajo, permite desplegar una concepción posfundacional de lo político. Esto se debe a que las revoluciones modernas plantean el problema del origen o de los fundamentos de un nuevo orden político. Arendt procede primeramente desmantelando los argumentos de los pensadores revolucionarios orientados a buscar un absoluto trascendente de los asuntos humanos como sustento. En su lugar, Arendt advierte que los asuntos humanos se caracterizan por ser contingentes y que no pueden detentar un fundamento absoluto. Sin embargo, esto no implica que lo político carezca absolutamente de fundamentos, sino que Arendt encuentra que todo nuevo origen se basa y resulta posible por la capacidad inherente a los seres humanos de empezar algo nuevo que nos viene dado con el nacimiento. De esta manera, el fundamento de lo político no resulta trascendente sino que se inscribe dentro de los asuntos humanos y remite a la libertad entendida como posibilidad de nuevos comienzos, por lo que resulta ser un fundamento contingente y relativo o inherente al ámbito humano. Asimismo, lo que salva la arbitrariedad del origen es el principio de acción que lo guía.

Por otra parte, hemos procurado destacar que la revolución recrea una tensión que resulta asimismo constitutiva de lo político: la tensión entre la aparición de la novedad y la fundación que le otorga estabilidad. Sin embargo, el desafío de lo político consiste en poder preservar dentro de lo establecido la posibilidad de surgimiento de lo nuevo. En esto fracasaron las revoluciones porque si bien fundaron

18 Esta referencia a la deliberación compartida tampoco nos debe inducir al error de subsumirla en una posición habermasiana, porque Arendt entiende la acción política como signada por un carácter conflictual y agonístico irreductible que no puede simplemente encasillarse en una concepción de la acción comunicativa orientada al consenso. Al respecto véase: Villa, 1996, pp.3-14 y 80-109. 
un cuerpo político no lograron mantener vivo el espíritu de participación activa que las habían hecho posible. De alguna manera, la persistencia y la actualidad de Sobre la revolución tiene que ver con la caracterización de lo político como una tensión entre lo nuevo y lo establecido, así como también con una reapertura de la discusión sobre las posibilidades de fundar algo nuevo, es decir, de un comienzo absolutamente nuevo. Esto resulta particularmente relevante en un momento en que el sistema democrático representativo parece haberse consolidado en cuanto a la cantidad de países que lo sustentan, pero al mismo tiempo parece resquebrajarse bajo las demandas recurrentes de profundización de la democracia - como en el caso de los indignados españoles, pero también por las movilizaciones multitudinarias en Brasil previas al mundial de fútbol -. Frente al anquilosamiento de nuestras democracias, resulta promisorio retomar el impulso arendtiano para reabrir el debate sobre el desafío de toda fundación y sobre la inherente novedad, contingencia y tensión de lo político en tanto exceso de lo establecido.

\section{Referencias}

Arendt, H. (1990). On Revolution. London: Penguin Books. Siglo XXI.

(1992). Sobre la revolución. Traducción de Pedro Bravo. Buenos Aires:

Birulés, F. (2007). Una herencia sin testamento. Hannah Arendt. Barcelona: Herder.

Canovan, M. (2000). "Hannah Arendt como pensadora conservadora”. En: F. Birulés (comp.). Hannah Arendt. El orgullo de pensar. Traducción de Javier Calvo Perales. Barcelona: Gedisa.

Di Pego, A. (2005). Lo social y lo público en la obra de Hannah Arendt. Reconsideraciones sobre una relación problemática. Intersticios (México), 10(22-23), pp.39-69.

- (2006). Poder, violencia y revolución en los escritos de Hannah Arendt. Algunas notas para repensar la política. Argumentos. Estudios Críticos de la Sociedad (México), 52, pp.101-123.

Disch, L. (2011). How could Hannah Arendt glorify the American Revolution and revile the French? Placing On Revolution in the historiography of the French and American Revolutions. European Journal of Political Theory, 10(3), pp.350-371.

Enegrén, A. (1994). “Revolución y fundación”. En: C. Hilb, (Comp.). El resplandor de lo público. En torno a Hannah Arendt. Traducción de Viviana Quiñones. Venezuela: Nueva Sociedad.

Forti, S. (1996). Vida del espíritu y tiempo de la polis. Hannah Arendt entre filosofia y política. Traducción de Irene Romera Pintor y Miguel Ángel Vega Cernuda. Madrid: Cátedra.

Habermas, J. (2000). Perfiles filosóficos-políticos. Traducción de Manuel Jiménez Redondo. Madrid: Taurus.

Hilb, C. (2012). El principio del inicio (reflexiones desordenadas). III Jornadas Internacionales Hannah Arendt: Narración, testimonio y opinión ¿Pensamiento posfundacional o nueva fundación de la política? Buenos Aires. 
Hobsbawm, E. (1965). On Revolution. By Hannah Arendt. History and Theory (Londres), $4(2)$, pp.252-258.

Honig, B. (1991). Declarations of Independences. Arendt and Derrida on the Problem of Founding a Republic. The American Political Science Review, 85(1), pp.97-113.

King, R. H. (2011). Hannah Arendt and the Concept of Revolution in the 1960s. New Formations, 71(3), pp.30-45.

Lefort, C. (2000). “Hannah Arendt y la cuestión de lo político”. En: F. Birulés (Comp.). Hannah Arendt. El orgullo de pensar. Traducción de Angela Ackermann. Barcelona: Gedisa.

Marchart, O. (2009). El pensamiento político posfundacional. La diferencia política en Nancy, Lefort, Badiou y Laclau. Traducción de Marta Delfina Álvarez. Buenos Aires: FCE.

(2011). “On Revolution / Über die Revolution”. En: W. Heuer, et. alt. Arendt Handbuch. Leben, Werk, Wirkung. Stuttgart: Metzler.

Muldoon, J. (2011). The Lost Treasure of Arendt's Council System. Critical Horizons, 12(3), pp.396-417.

Smola, J. (2012). «Pensar lo que hacemos». La filosofía política frente a la fundación. En: III Jornadas Internacionales Hannah Arendt: Narración, testimonio y opinión ¿Pensamiento posfundacional o nueva fundación de la política?, Buenos Aires.

Villa, D. R. (1996). Arendt and Heidegger. The Fate of the Political. New Jersey: Princeton University Press.

Wellmer, A. (2006). "Arendt on revolution". En: Cambridge Companion to Hannah Arendt. Cambridge: Cambridge University Press. . (2008). “Hannah Arendt y la revolución”. En: Hannah Arendt. El legado de una mirada. Traducción de Javier Eraso Ceballos. Madrid: Sequitur. 